JURNAL ILMIAH KOMPUTERISASI AKUNTANSI, Vol. 14, No. 2,Desember 2021, pp. 215 - 229

\title{
Perancangan Sistem Informasi Akuntansi Penghapusan Aset Tetap Pada BPKAD Pemerintah Kota Cimahi
}

\author{
Khaerun Nissa Nur Fauziah ${ }^{1}$, Perwito ${ }^{2}$, Rini Suwartika Kusumadiarti ${ }^{3}$ \\ ${ }^{1}$ Politeknik Piksi Ganesha \\ Jl. Gatot Subroto No.301 Bandung, No telp : (022) 87340030, e-mail : knnfauziah@piksi.ac.id \\ ${ }^{2}$ Politeknik Piksi Ganeha \\ Jl. Gatot Subroto No.301 Bandung, No telp : (022) 87340030, e-mail : Perwitoe@ gmail.com \\ ${ }^{3}$ Politeknik Piksi Ganeha \\ Jl. Gatot Subroto No.301 Bandung, No telp : (022) 87340030, e-mail : rinisuwartika@ gmail.com
}

\section{ARTICLE INFO}

Article history:

Received 30 September 2021

Received in revised form 2 Nov 2021

Accepted 10 Nov 2021

Available online 1 Des 2021

\section{ABSTRACT}

With the rapid development of technology, the role of information systems is very important. One of the organizations that feel the benefits of an information system is government agencies. The process of deleting fixed assets is still using Microsoft Excel so its performance is still not effective. The problem that arises is when recording assets that will be deleted but the physical condition of the assets does not exist and another problem is that there are still many unrecorded assets for deletion so that employees have to look for asset data and become ineffective. This problem can be solved by designing an information system for the disposal of fixed assets using the waterfall and web-based model, the PHP programming language and MySQL as the database. The method used is the UML (Unified Modelling System) system 
modelling, namely Activity Diagrams and Use Case Diagram. The design of this information system aims to assist BPKAD employees in handling the asset write-off process and producing the required reports.

Keywords: Planning; Information System; Fixed assets; UML.

\begin{abstract}
Abstrak
Dengan adanya perkembangan teknologi yang pesat, peran sistem informasi menjadi sangat penting. Salah satu organisasi yang merasakan manfaat adanya sistem informasi yaitu instansi pemerintahan. Proses penghapusan pada aset tetap masih menggunakan Microsoft Excel sehingga kinerjanya masih belum efektif. Masalah yang muncul yaitu ketika pencatatan aset yang akan dilakukan penghapusan tetapi kondisi fisik asetnya tidak ada dan masalah lainnya yaitu masih banyak aset yang tidak tercatat untuk dilakukan penghapusan sehingga para pegawai harus mencari data aset tersebut dan menjadi tidak efektif. Masalah tersebut dapat diatasai dengan merancang sistem informasi penghapusan aset tetap dengan menggunakan model waterfall dan berbasis web, bahasa pemograman $P H P$ dan $M y S Q L$ sebagai databasenya. Metode yang digunakan yaitu permodelan sistem UML (Unified Modelling Sistem) yaitu Activity Diagram dan Use Case Diagram. Perancangan sistem informasi ini bertujuan untuk membantu pegawai BPKAD dalam menangani proses penghapusan aset dan menghasilkan laporan yang dibutuhkan.
\end{abstract}

Kata Kunci : Perancangan; Sistem Informasi; Aset Tetap; UML.

\title{
1. PENDAHULUAN
}

Sistem Informasi menjadi salah satu peran yang penting, karena adanya perkembangan teknologi yang semakin pesat. Banyak organisasi yang sudah merasakan manfaat dari perkembangan teknologi, salah satunya yaitu instansi pemerintahan. Dengan adanya sistem informasi ini, diharapkan dapat memperkecil kesalahan yang akan terjadi dan juga lebih memudahkan dalam pekerjaanya. Salah satu sistem informasi yang harus disediakan dengan baik yaitu informasi tentang aset-aset, salah satunya yaitu aset tetap. 
Aset tetap merupakan aset berwujud yang masa manfaatnya lebih dari 1 (satu) tahun untuk digunakan pada kegiatan pemerintahan atau juga dapat dimanfaatkan oleh masyarakat umum [1]. Terdapat beberapa kelompok aset tetap, diantaranya yaitu gedung dan bangunan, tanah, jalan irigasi dan jaringan, kontruksi dalam pengerjaan, peralatan dan mesin, dan aset tetap lainnya.

Ada beberapa proses untuk mengelola aset daerah, salah satunya yaitu penghapusan. Penghapusan adalah aktivitas menghapus barang/aset milik daerah dari daftar barang dengan tujuan untuk membebaskan pengelola barang, pengguna barang, maupun kuasa pengguna barang dari tanggung jawab administrasi dan fisik atas barang yang berada dalam penguasaannya [2].

Pada BPKAD Pemerintah Kota Cimahi, penghapusan dilakukan secara semikomputerisasi. Sehingga, dalam penggunaannya masih sering terdapat kesalahan pada saat mencatat aset yang akan dihapuskan. Kesalahan tersebut diantaranya yaitu pada saat data aset sudah terdaftar untuk dilakukan penghapusan, namun ternyata kondisi fisik dari aset tersebut tidak ada. Adapun kesalahan yang lainnya yaitu banyak aset yang tidak tercatat padahal aset tersebut seharusnya sudah harus dilakukan penghapusan, sehingga para pegawai harus mencari data aset tersebut dan membutuhkan waktu yang cukup lama. Proses penghapusan ini harus dilakukan agar tidak ada lagi intansi yang mengajukan biaya untuk pemeliharaan dan pengakuan atas aset yang dihapuskan. Pencatatan untuk penghapusan atau penghentian aset tetap ini yaitu dengan menghitung penyusutan dan nilai laba rugi penjualan aset tetapnya, setelah itu mencatat untuk penghentian atau penghapusan asetnya.

Penelitian Maria Rosario Borroek di STIKOM Dinamika Bangsa bertujuan agar pengelolaan aset terutama penjualan dan penghapusan aset dapat berjalan lebih optimal. Penelitiannya menghasilkan prototype sistem dengan model pengembangan sistem yaitu UML, diantaranya yaitu class diagram, use case diagram dan activity diagram [3]. 


\section{TINJAUAN PUSTAKA}

\subsection{Sistem Informasi Akuntansi}

Menurut Wilkinson sistem infromasi akutansi adalah suatu rangkaian yang didalamnya mencakup Tindakan koordinasi sumber daya (equipment, personal, data, materials, funds, and suppliers) yang dapat menghasilkan sebuah keluaran berupa data ekonomik dikonversi sampai menjadi informasi yang bermanfaat bagi pihakpihak berkepentingan untuk melaksanakan kegiatan maupun aktivitas suatu entitas [4].

\subsection{Penghapusan Aset}

Proses terakhir dalam perjalanan hidup aset daerah yaitu penghapusan. Menurut Sugiama, aset yang dapat dihapuskan atau disposal yaitu aset yang sudah tidak layak berdasarkan pertimbangan ekonomi maupun fungsinya [5]. Penghapusan ini memberikan dampak terhadap suatu instansi yaitu tidak ada lagi pengajuan biaya pemeliharaan dan pengakuan atau pengungkapan terhadap aset daerah yang dihapuskan.

Terdapat 2 (dua) cara penghapusan aset, yaitu dapat dilakukan secara lelang dengan menjual aset-aset melalui kantor pelelangan negara dan dapat dilakukan pemusnahan terhadap aset yang ditinjau dari segi uang dengan mempertimbangkan faktor-faktor pemusnahan.

\section{METODOLOGI PENELITIAN}

\section{A. Metode Penelitian}

Metode penelitiannya menerapkan pada pendekatan kualitatif. Metode penelitian kualitatif menurut Sugiyono (2013) merupakan metode untuk meneliti pada kondisi obyek yang sifatnya alamiah, Pengumpulan datanya dapat dilakukan triangulasi atau gabungan. Penelitian kualitatif ini menekankan pada makna [6].

Perancangan Sistem Informasi Akuntansi Penghapusan Aset Tetap Pada BPKAD Pemerintah Kota Cimahi (Khaerun Nisa Nur Fauziah) 


\section{B. Metode Pengumpulan Data}

Pengumpulan datanya dilakukan dengan menggabungkan antara data sekunder dan data primer. Data primer dapat dilakukan dengan melakukan wawancara (Interview) dengan salah satu pihak yang menangani tentang penghapusan aset di BPKAD yang bertujuan agar mendapatkan informasi atau data yang akurat. Penulis juga melakukan pengamatan (Observation) terhadap objek yang diteliti.

Data sekunder yang dikumpulkan penulis yaitu dengan membaca kartu inventaris barang (KIB), membaca SK, dan membaca tentang kendaraan yang di lelang di BPKAD.

\section{Metode Pengembangan Sistem}

Pengembangan sistem yang dipilih yaitu menggunakan model air terjun (Waterfall) atau bisa juga disebut dengan Linear Sequential Model. Metode Waterfall ini mengusulkan pendekatan yang sistematis atau berurutan. Model waterfall dipilih karena sesuai dengan kebutuhan perancangan yang dilakukan oleh penulis.

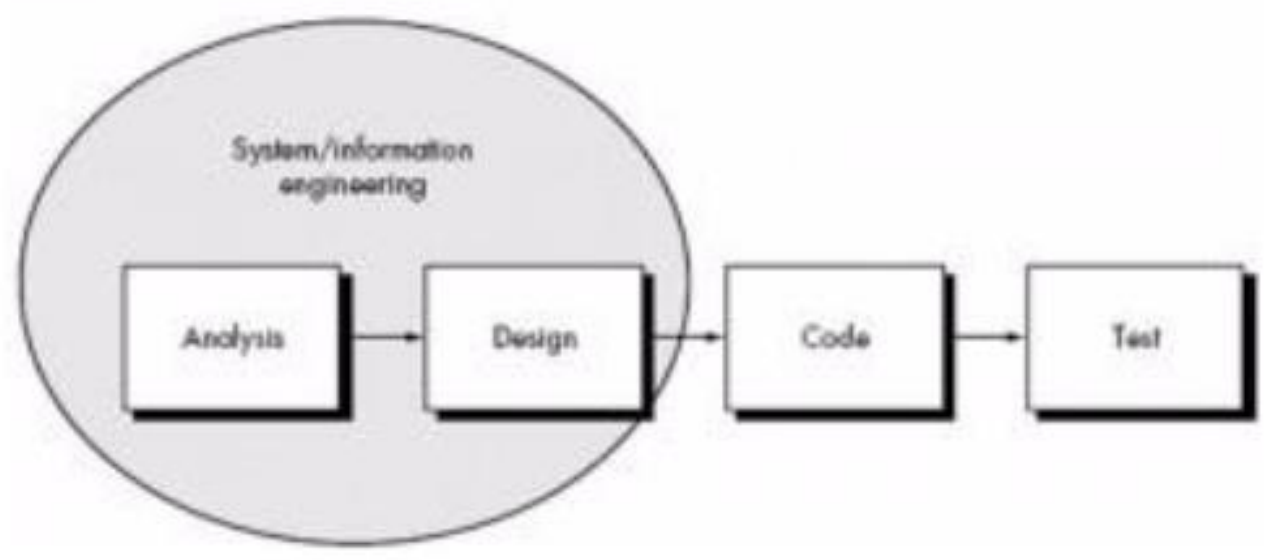

Gambar 1. Model Waterfall [7]

a. Analisis Kebutuhan

Perancangan Sistem Informasi Akuntansi Penghapusan Aset Tetap Pada BPKAD Pemerintah Kota Cimahi (Khaerun Nisa Nur Fauziah) 
Berdasarkan analisis sistem yang sedang berjalan, yang menjadi kebutuhan untuk Perancangan Sistem Informasi Penghapusan Aset Tetap Pada BPKAD Pemerintah Kota Cimahi adalah sebagai berikut :

1. Sistem terdapat fungsi login dan logout untuk admin.

2. Sistem menyediakan fungsi mengolah data penghapusan aset yang dapat dilakukan oleh admin seperti menambah data, edit data, dan hapus data.

3. Sistem menyediakan fungsi data aset yang di usulkan untuk dilakukan penghapusan

4. Sistem menyediakan fungsi upload SK penghapusan

5. Sistem menyediakan fungsi data aset yang telah dihapuskan

6. Sistem menyediakan fungsi laporan usulan penghapusan dan penghapusan aset

\section{b. Desain Sistem}

Tahapa ini dilakukan perancangan desain dengan menggunakan UML (Unified Modelling Sistem). Setelah itu akan di implementasikan menggunakan $P H P$ dan $M y S Q L$. Alat bantu yang digunakan dalam perancangan ini yaitu Visual Studio Code.

\section{c. Pengkodean}

Pada tahap ini, kode program diimplementasikan kedalam bentuk perintah-perintah yang dimengerti oleh komputer. Perancangan ini menggunakan PHP sebagai bahasa pemogramannya.

\section{d. Pengujian Sistem}

Yang terakhir yaitu melakukan uji sistem dengan 2 (dua) cara yaitu, Black Box Testing dan White Box Testing. Black Box pengujiannya didasarkan pada detail aplikasi seperti tampilan, fungsi, dan kesesuaian alur agar tidak terjadi eror. Sedangkan White Box didasarkan pada kode-kode programnya, dan menganalisis terdapat kesalahan atau tidak.

\section{HASIL DAN PEMBAHASAN}

\subsection{Analisis Sistem yang Sedang Berjalan}

Perancangan Sistem Informasi Akuntansi Penghapusan Aset Tetap Pada BPKAD Pemerintah Kota Cimahi (Khaerun Nisa Nur Fauziah) 
Pengolahan data penghapusan aset tetap di BPKAD Pemeritah Kota Cimahi menggunakan Microsoft Excel sehingga masih sering terjadi kesulitan atau kesalahan dalam pengolahan datanya. Pengolahan data penghapusan aset ini dimulai dari Satuan Kerja Perangkat Daerah (SKPD) mengajukan usulan penghapusan kepada pengurus bidang penghapusan. Setelah disetujui, pengurus akan memeriksa data administrasi dan fisik aset lalu pengurus akan mengeluarkan berita acara dan nota dinas penghapusan yang akan disampaikan kepada walikota. Walikota akan mengeluarkan surat persetujuan walkot yang kemudian akan disampaikan kepada KPNL/KJPP untuk dilakukan penilaian dan pendaftaran lelang. Hasil lelang akan disampaikan kepada pengurus bidang penghapusan lalu pengurus akan memproses SK penghapusan setelah itu aset resmi dihapuskan.

\section{Evaluasi Sistem yang sedang berjalan}

\begin{tabular}{|l|l|l|l|}
\hline No. & Masalah & Penyelesaian \\
\hline 1 & $\begin{array}{l}\text { Proses penghapusan aset tetap } \\
\text { masih semi-komputerisasi }\end{array}$ & $\begin{array}{l}\text { Dengan sistem informasi, proses } \\
\text { penghapusan dapat dilakukan } \\
\text { dengan mudah dan praktis }\end{array}$ \\
\hline 2 & $\begin{array}{l}\text { Keamanan data masih belum } \\
\text { terjamin }\end{array}$ & $\begin{array}{l}\text { Dengan sistem informasi akan } \\
\text { menjamin keamanan data menjadi } \\
\text { lebih baik }\end{array}$ \\
\hline 3 & $\begin{array}{l}\text { Laporan penghapusan aset } \\
\text { masih belum akurat dan } \\
\text { membutuhkan waktu yang lama }\end{array}$ & $\begin{array}{l}\text { Adanya sistem informasi akan } \\
\text { mampu membuat laporan secara } \\
\text { cepat dan tepat }\end{array}$ \\
\hline
\end{tabular}

\subsection{Perancangan Sistem}

Perancangan sistem merupakan gambaran sekumpulan aktivitas bagaimana sistem yang akan dibuat berjalan dengan baik. Dalam perancangan ini, permodelan sistem yang digunakan yaitu UML (Unified Modelling Sistem) diantaranya ada Activity Diagram dan Use Case Diagram.

\subsubsection{Use Case Diagram}

Menurut Tohari (2014), Use Case adalah rangkaian yang berkaitan satu sama lain dengan tujuan membentuk sebuah sistem secara sistematis yang akan diawasi oleh actor [8]. 


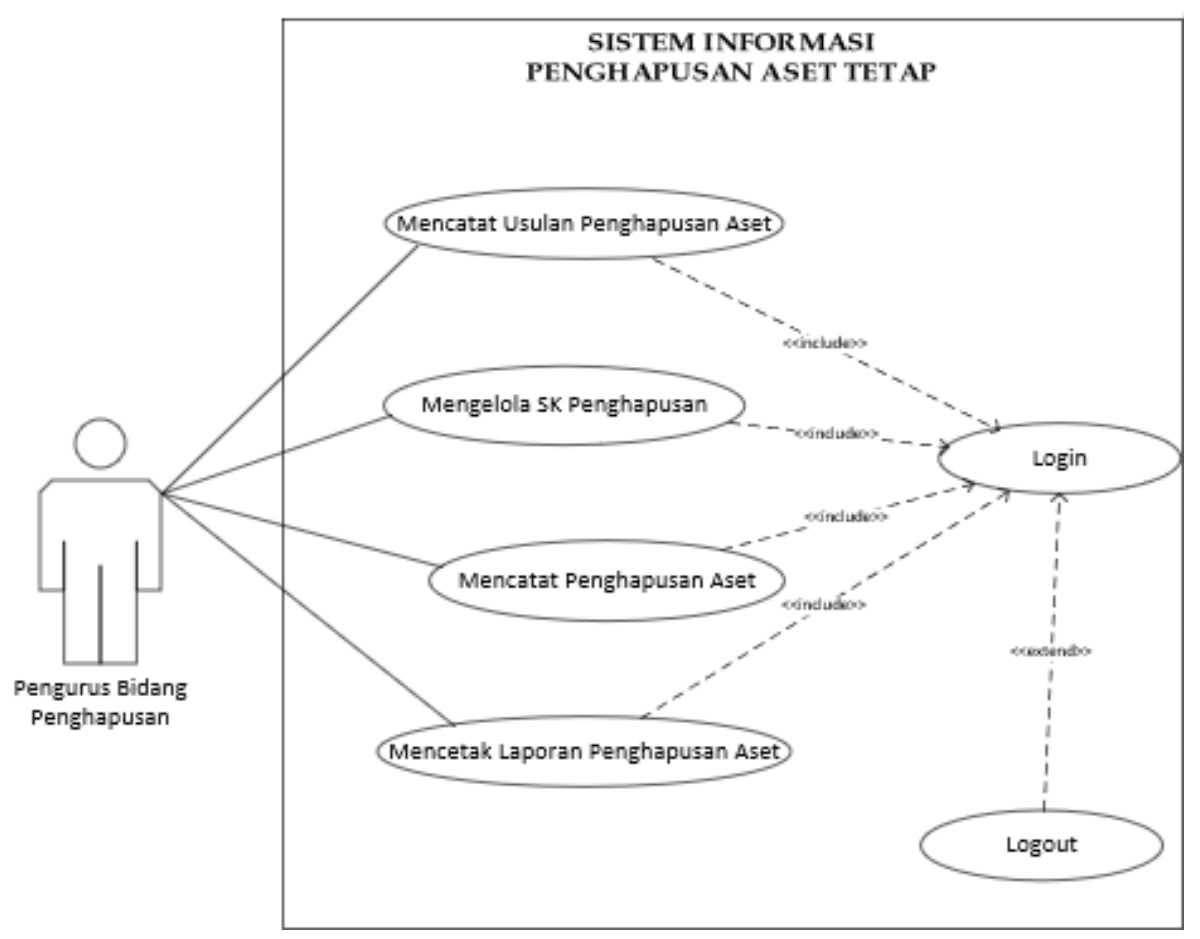

\subsubsection{Activity Diagram}

\section{Gambar 2. Use Case Diagram}

Menurut Tohari(2014) Activity Diagram merupakan permodelan suatu proses bisnis dan urutan aktivitas ke status maupun aktivitas ke aktivitas yang lainnya [8]. 


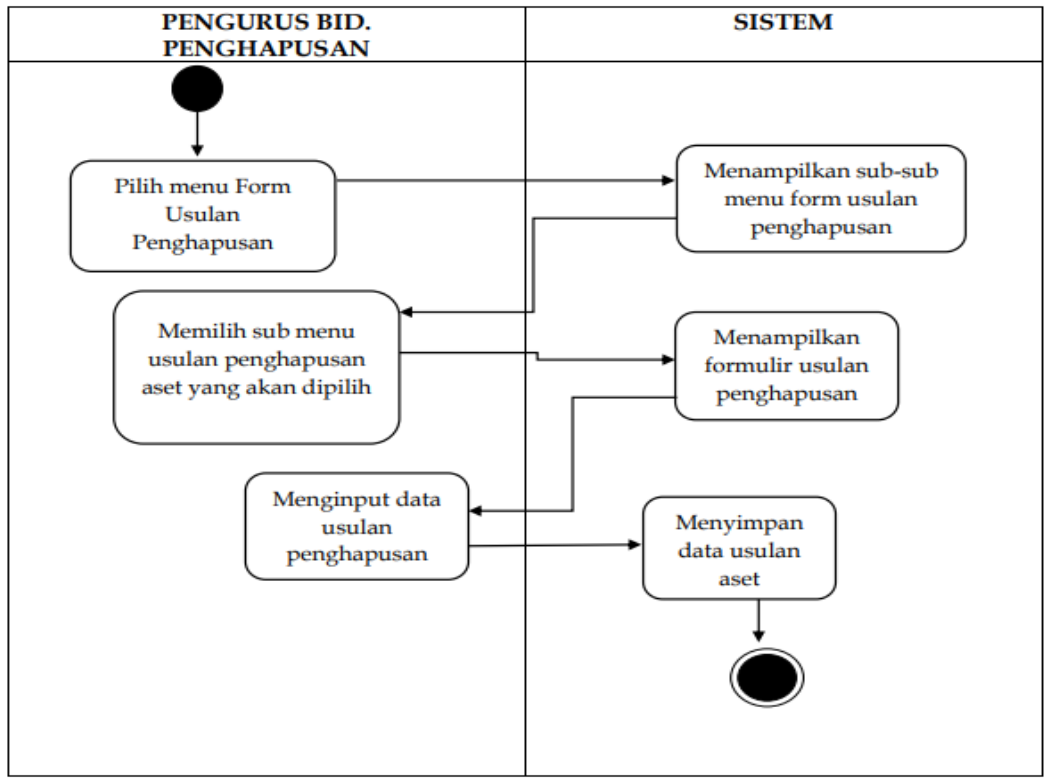

Gambar 3. Activity Diagram Usulan Penghapusan

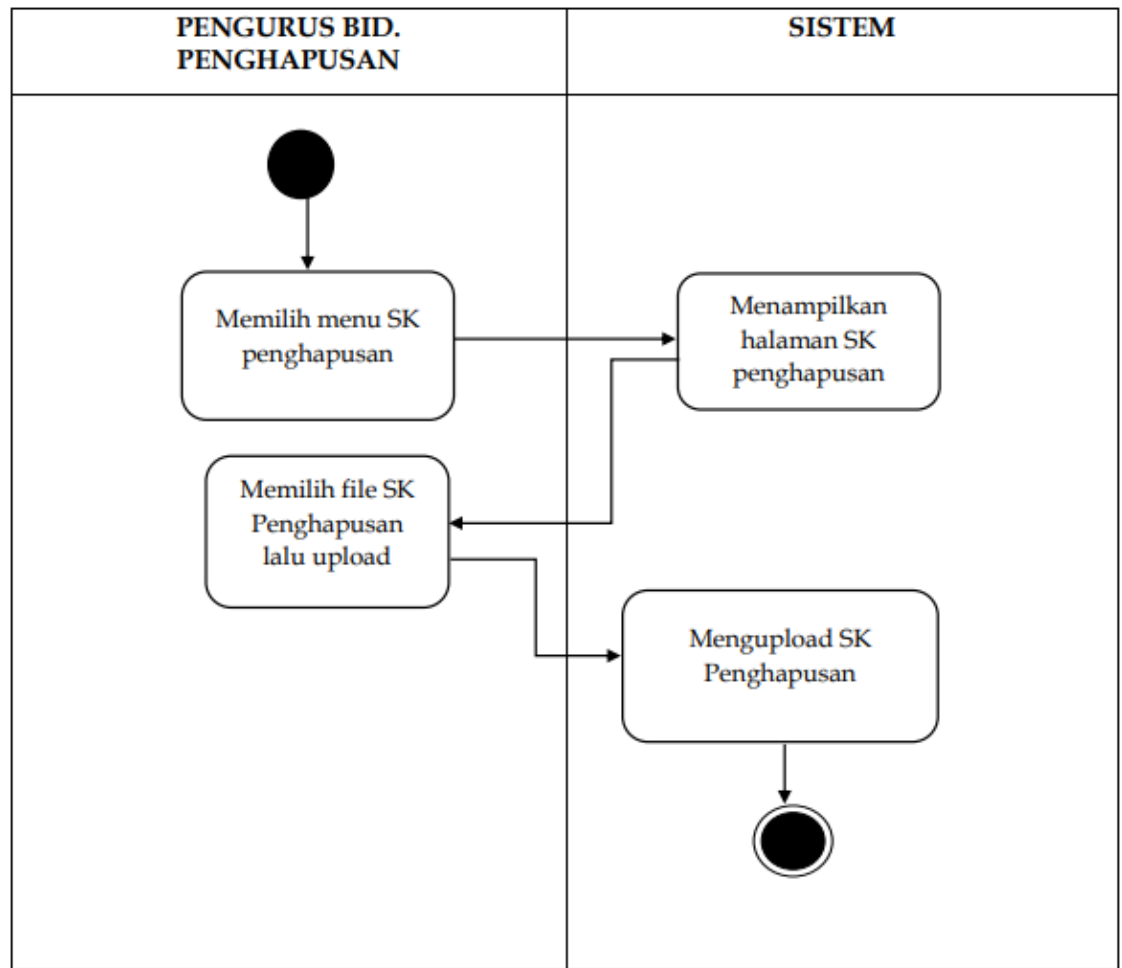

Gambar 4. Activity Diagram SK Penghapusan

Perancangan Sistem Informasi Akuntansi Penghapusan Aset Tetap Pada BPKAD Pemerintah Kota Cimahi (Khaerun Nisa Nur Fauziah) 


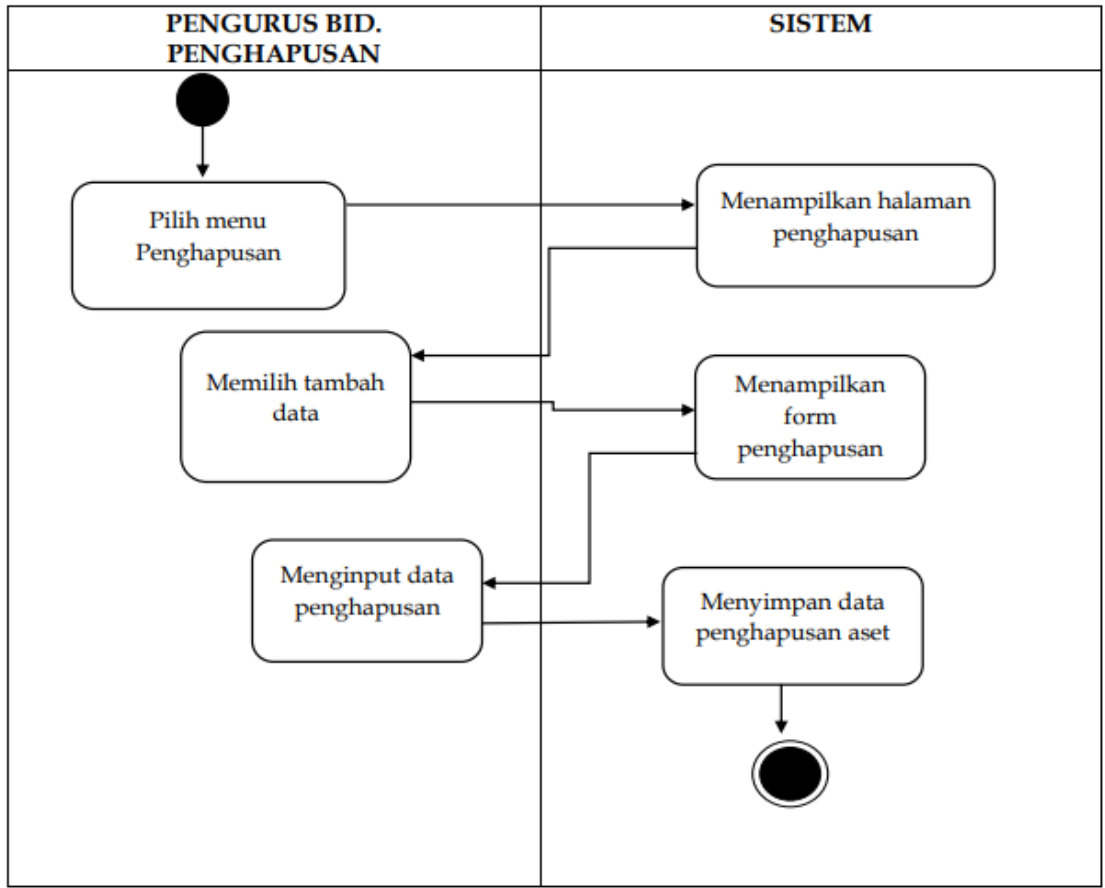

Gambar 5. Activity Diagram Pencatatan Penghapusan

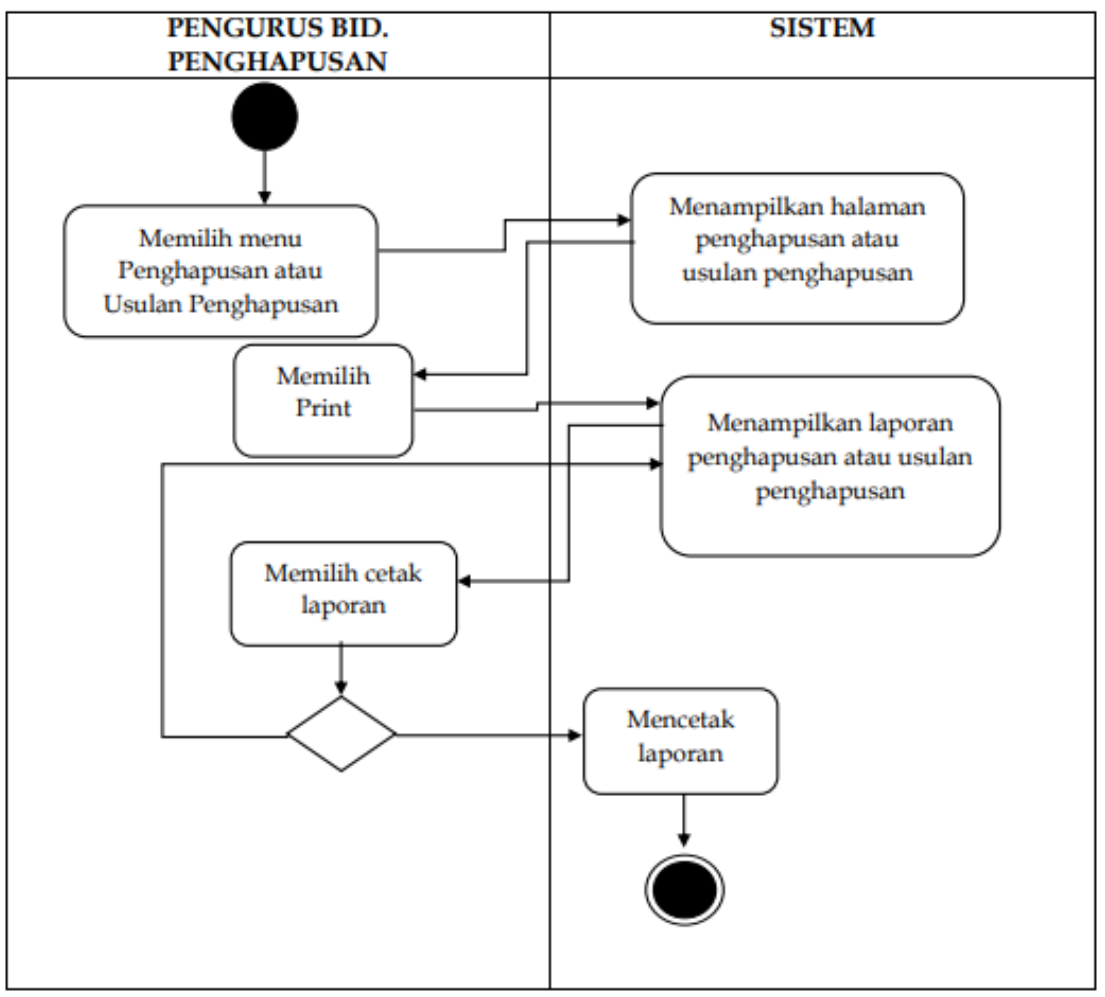

Perancangan Sistem Informasi Akuntansi Penghapusan Aset Tetap Pada BPKAD Pemerintah Kota Cimahi (Khaerun Nisa Nur Fauziah) 


\section{Gambar 6. Activity Diagram Mencetak Laporan}

\subsubsection{Rancangan Antarmuka (Interface)}

Berikut merupakan tampilan dari hasil perancangan sistem informasi akuntansi aset tetap menggunakan $P H P$ dan MySQL. Tampilan yang dimulai dari login sampai dengan print laporan terdapat pada gambar 7 sampai dengan gambar 11. Pada gambar 7 pegawai harus masuk kedalam sistem terlebih dahulu yaitu dengan memasukan username dan password, gambar 8 merupakan tampilan dashboard dimana terdapat menu logout dan menu untuk masuk ke penginputan data seperti usulan penghapusan, sk penghapusan dan penghapusan. Pada gambar 9 terdapat tampilan usulan penghapusan yang di dalamnya terdapat menu tambah data, print, ubah dan hapus. Gambar 10 merupakan tampilan sk penghapusan yang di dalamnya terdapat menu untuk mengupload file sk penghapusan, pada gambar 11 tampilan penghapusan yang dimana terdapat menu tambah data, print, ubah, hapus dan informasi bahwa aset tersebut dihapuskan atau tidak. Gambar 12 merupakan tampilan print laporan usulan penghapusan dan gambar 13 tampilan print penghapusan.

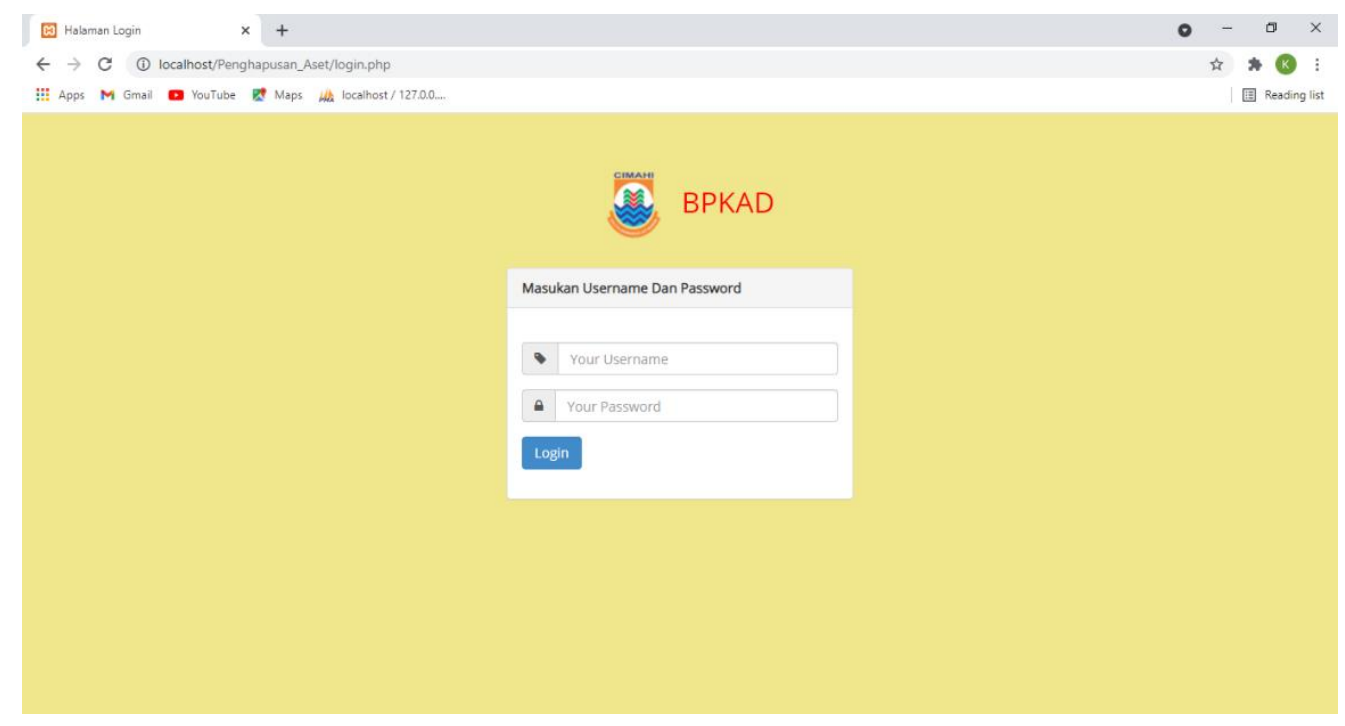

Gambar 7. Tampilan Login

Perancangan Sistem Informasi Akuntansi Penghapusan Aset Tetap Pada BPKAD Pemerintah Kota Cimahi (Khaerun Nisa Nur Fauziah) 


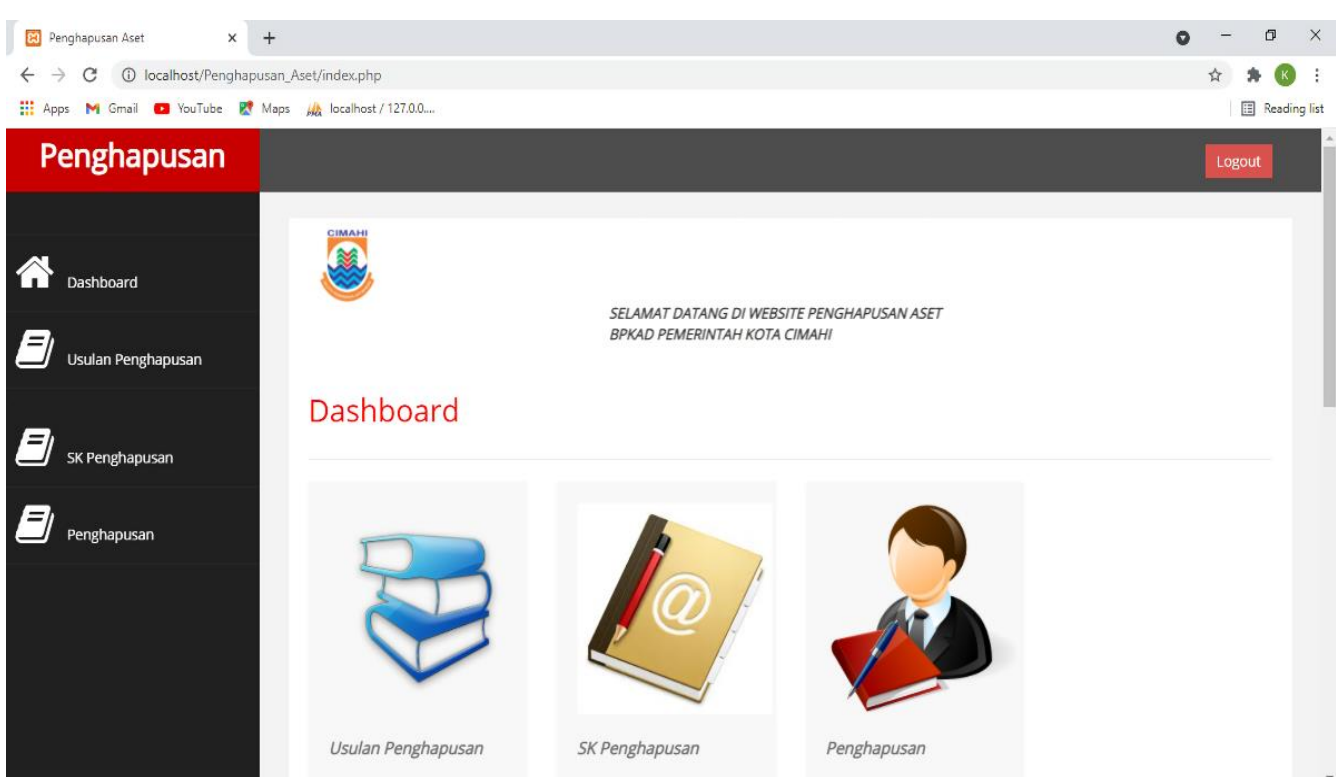

Gambar 8. Tampilan Dashboard

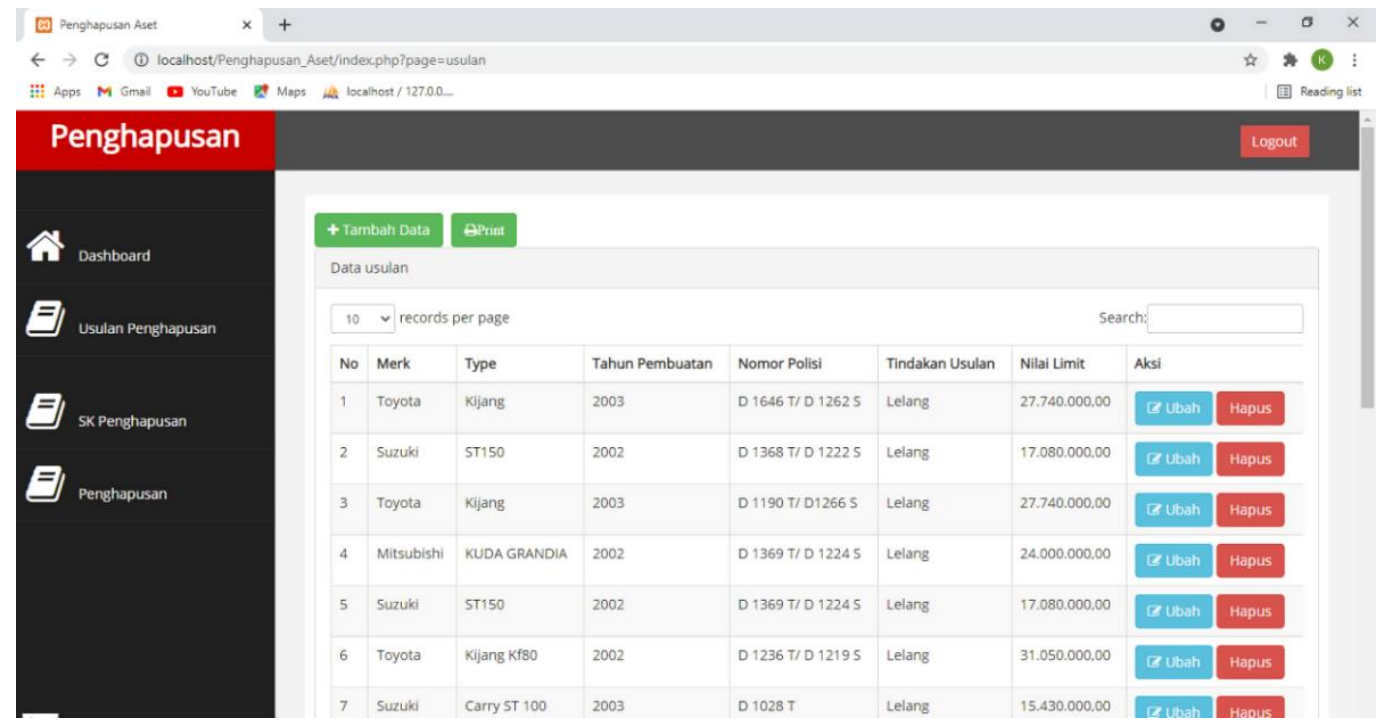

Gambar 9. Tampilan Usulan Penghapusan

Perancangan Sistem Informasi Akuntansi Penghapusan Aset Tetap Pada BPKAD Pemerintah Kota Cimahi (Khaerun Nisa Nur Fauziah) 


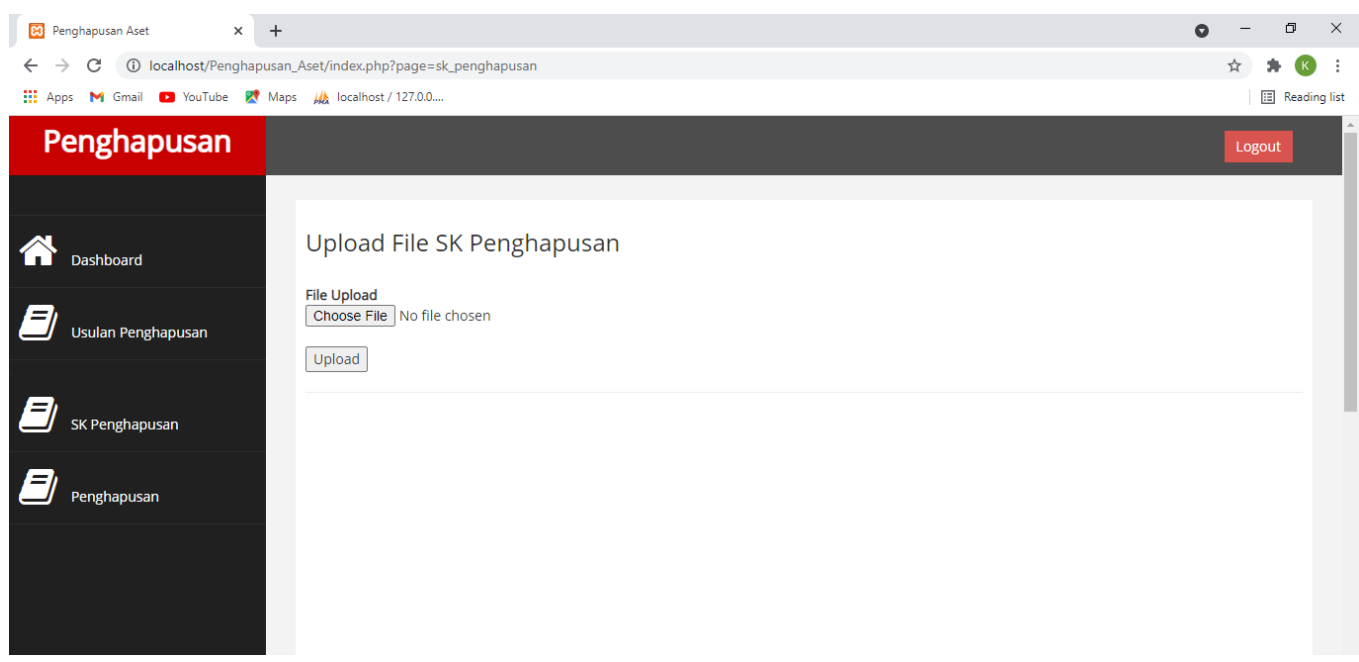

Gambar 10. Tampilan SK Penghapusan

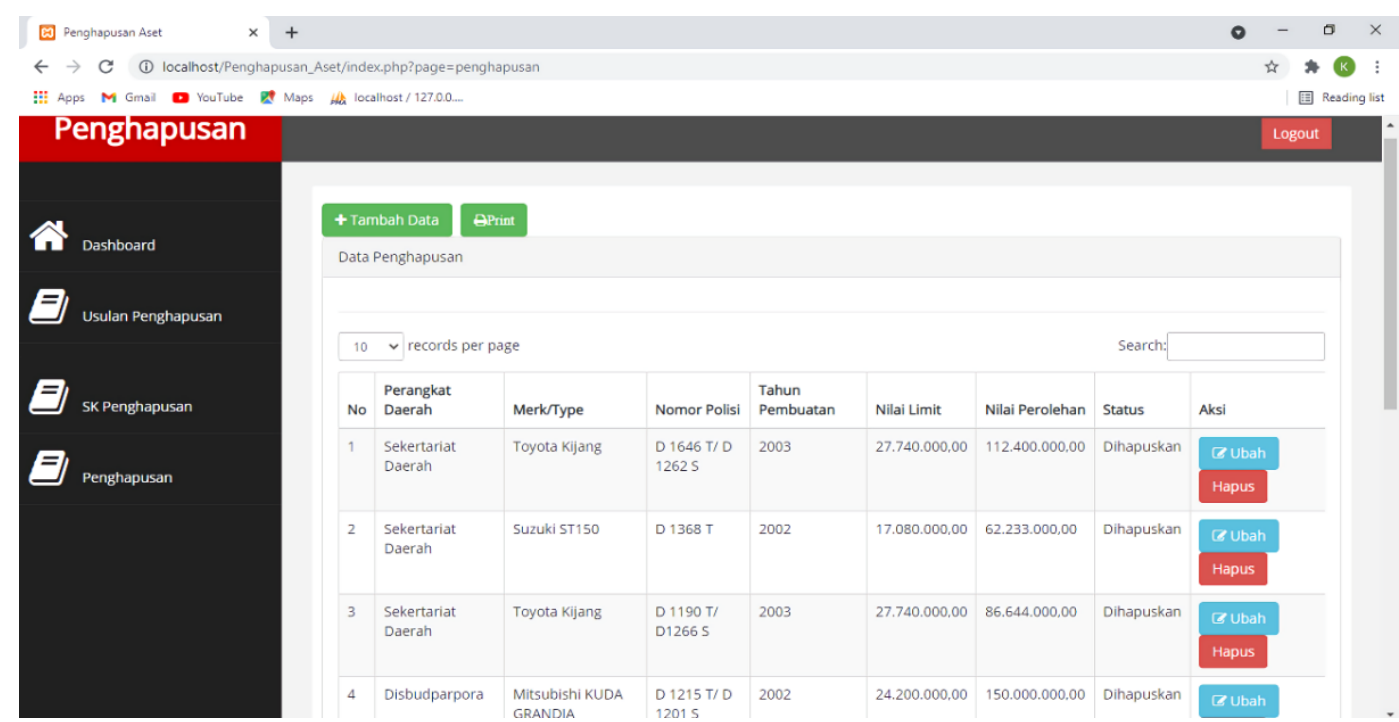

Perancangan Sistem Informasi Akuntansi Penghapusan Aset Tetap Pada BPKAD Pemerintah Kota Cimahi (Khaerun Nisa Nur Fauziah) 


\section{Gambar 11. Tampilan Penghapusan}

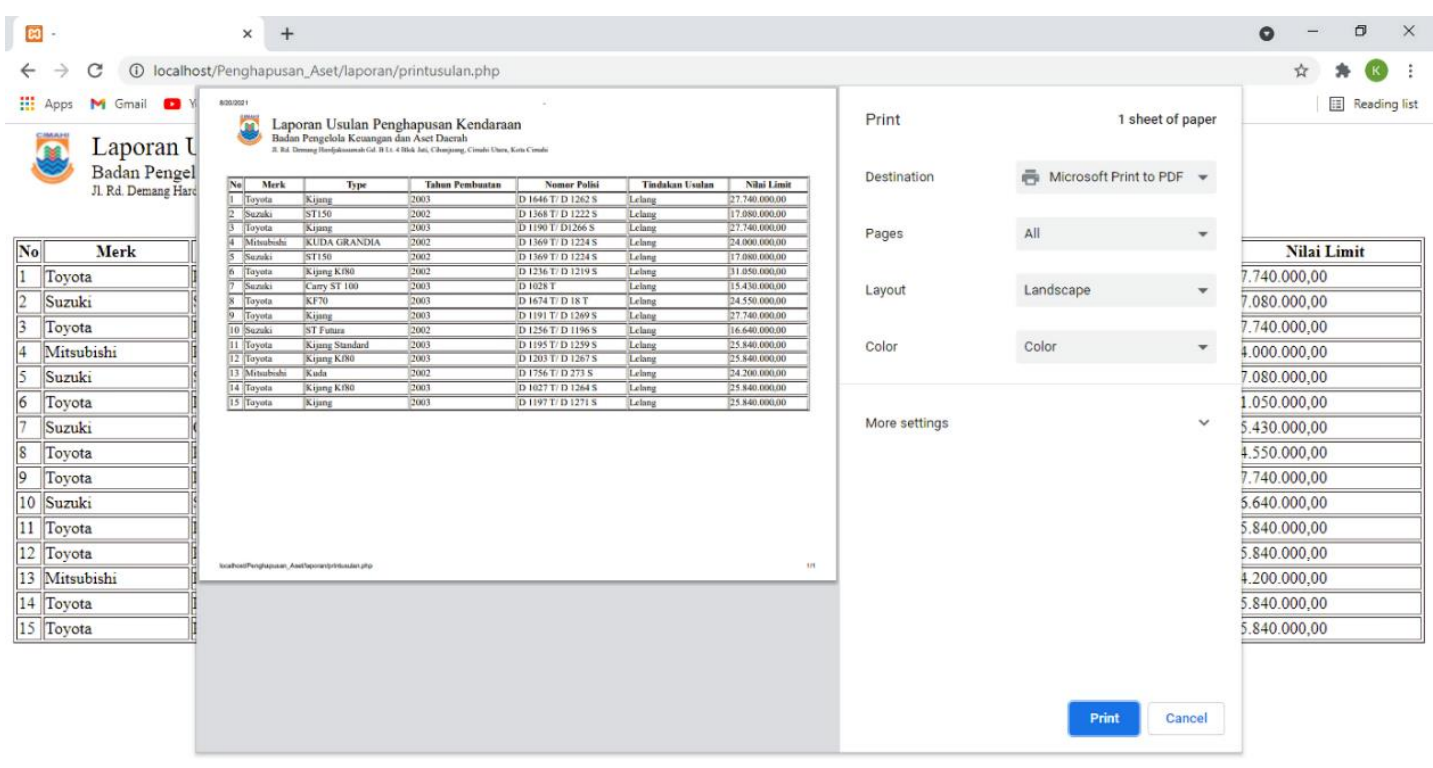

Gambar 12. Tampilan Print Laporan Usulan Penghapusan 


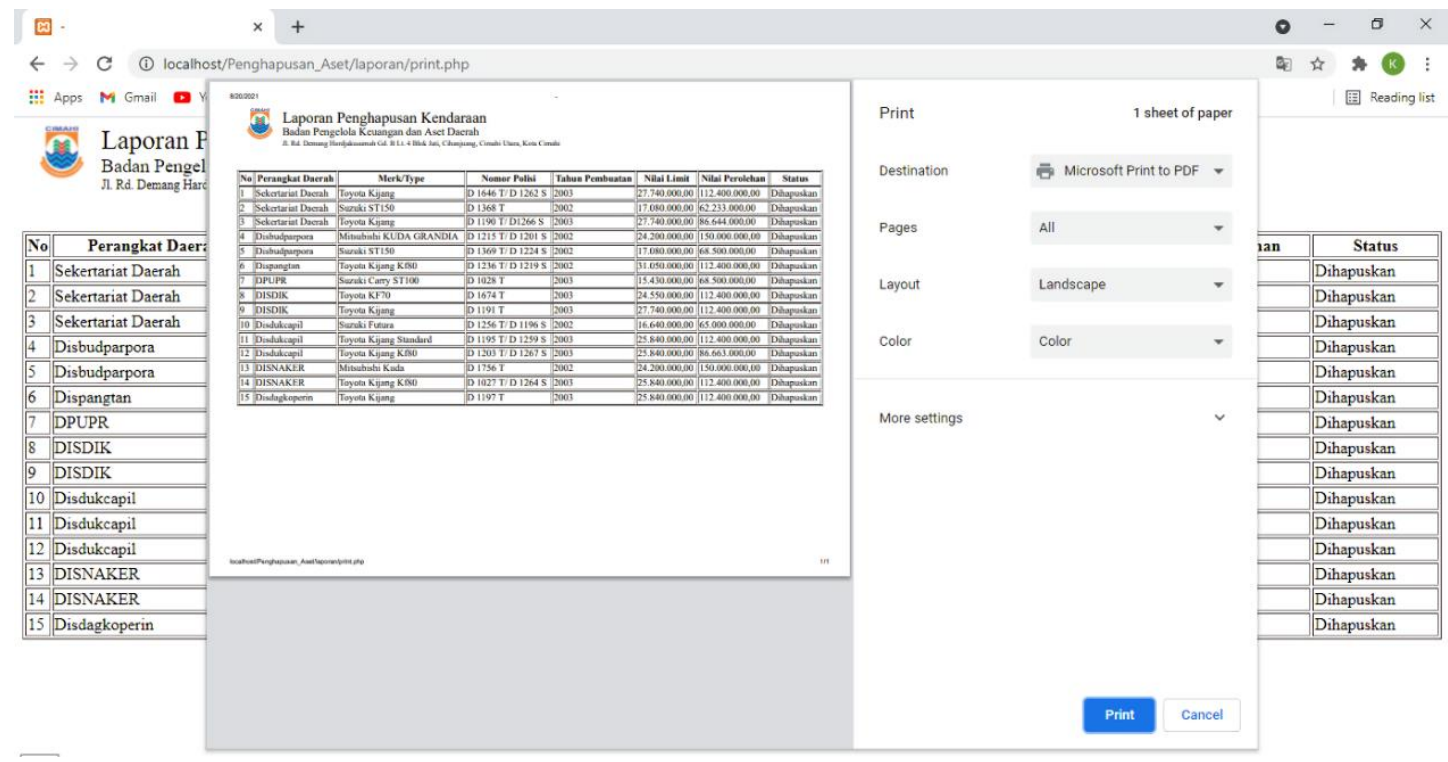

Gambar 13. Tampilan Print Laporan Penghapusan

\section{KESIMPULAN DAN SARAN}

\section{Kesimpulan :}

1. Proses penghapusan aset di BPKAD masih sebagian dilakukan secara manual atau semi-komputerisasi sehingga prosesnya masih belum optimal.

2. Perancangan sistem yang dilakukan peneliti yaitu menggunakan bahasa pemograman $P H P$ dan $M y S Q L$, yang bertujuan agar dapat membantu pegawai BPKAD dalam pengelolaan data-data aset yang akan dilakukan penghapusan.

\section{Saran :}

1. Disarankan sistem informasi yang telah dirancang ini dapat dijadikan sebagai referensi untuk proses penghapusan aset.

2. Diharapkan adanya pengembangan pada sistem yang telah dirancang agar dapat diterapkan sesuai dengan kebutuhan. 


\section{DAFTAR PUSTAKA}

[1] Komite Standar Akuntansi Pemerintah, "Standar Akuntansi Pemerintahan Pernyataan Nomor 7 Tentang Akuntansi Aset Tetap," PSAP O7 tentang Aset Tetap, no. 07, 2005.

[2] P. M. D. Negeri, "Permendagri Nomor 19 Tahun 2016,” no. 547, 2016.

[3] M. R. Borroek, "Perancangan Sistem Informasi Manajemen Aset pada STIKOM Dinamika Bangsa Jambi (Studi Kasus: Penjualan dan Disposal Aset Tetap)," J. Ilm. Media SISFO, vol. 8, no. 2, pp. 61-74, 2017.

[4] Y. M. \& I. Dewi, Kualitas Penerapan Sistem Informasi Akuntansi Manajemen Pada Entitas Sektor Publik. Surabaya: Scopindo Media Pustaka, 2020.

[5] D. I. Sekretariat, D. Provinsi, R. Tahun, E. Dwikawulandariyahoocom, and T. Fax, "No Title," vol. 7, pp. 1-15, 2017.

[6] Sugiyono, Metode Penelitian Kuantitatif, Kualitatif, dan R\&D. Bandung: Alfabeta.CV, 2013.

[7] I. Yunita and J. Devitra, "Analisis dan Perancangan Sistem Informasi Manajemen Aset Pada SMK Negeri 4 Kota Jambi,” J. Manaj. Sist. Inf., vol. 2, no. 1, pp. 278-294, 2017.

[8] H. Tohari, Analisis Serta Perancangan Sistem Informasi Melalui Pendekatan UML. Yogyakarta: ANDI OFFSET, 2014. 